\title{
What the NHS is learning from the British army in the covid-19 crisis
}

\author{
"Military planning" has become a feature of efforts to tackle covid-19. But what is it-and how has it \\ proved to be what we need now? Geoff Watts and Emma Wilkinson report
}

\author{
Geoff Watts journalist $^{1}$, Emma Wilkinson journalist ${ }^{2}$ \\ 'London; ${ }^{2}$ Sheffield
}

Governments around the world have been seeking the help of the military in tackling the spread of covid-19. Some of these interventions have been substantial: as early as the beginning of March, the Chinese state news agency Xinhua was reporting that 10000 military medics were already "working at the front line" and that 3000 beds had been set up by 63 military hospitals for treating infected patients. ${ }^{1}$

The UK Ministry of Defence is no exception to this involvement in what are normally civilian affairs. From building new hospitals to delivering bulk oxygen supplies and taking the strain off employees at hard pressed NHS supply depots, soldiers have been in evidence.

A large, disciplined, and flexible workforce able to step in and provide some muscle at short notice is clearly valuable. Less immediately obvious is the benefit of another element of the ministry's assistance: the deployment of military planners, not least in the transformation of large enclosed spaces-conference centres such as London's Excel Centre-into temporary hospitals. The NHS has planners of its own, so what are the distinguishing features of the military approach?

\section{Planning not plans}

Richard Jones is a consultant cardiologist at Queen Alexandra Hospital in Portsmouth, host to the country's largest Ministry of Defence hospital unit. He works closely with military personnel: with them, but not of them, he is a source of a knowledgeable but detached view of the military. "What the military do so well is planning for huge surges, because that's in the nature of their challenges," he says.

"In the health service we tend to plan new services or service changes over months or years; engagement with patients and other service users takes time." Because the changes in demand are mostly gradual — population ageing, for example—this time can be available.
By contrast, planning for sudden, fast moving events like epidemics is, as Jones puts it, the military's stock in trade. "They spend their lives working through unexpected scenarios ... The NHS does have major incident plans, and every so often they're rehearsed. But this [the pandemic] is on a rather different scale."

Mark Norton, a former lieutenant colonel in the British army, talks of a distinctive "philosophy of planning" that puts an emphasis on process. "The process of planning is what's important rather than the actual plan as an output," he says. This perhaps counterintuitive conclusion is a consequence of what Norton refers to as the great truism of military planning: "that no plan survives contact with the enemy."

Military planning thus emphasises the continual gathering of intelligence that might prompt changes to a plan. Norton comments, "It's a different philosophy to the one I've encountered in business, where a plan is usually made at the beginning of the year, and then you just work it through."

\section{Scale and speed}

Tim Whittlestone, chief medical officer of the 300 bed Bristol Nightingale Hospital-which was opened up to NHS staff for clinical training after just two weeks-has experienced this flexibility first hand. At first he envisaged soldiers coming in with hammers to put everything together, he admits. In reality, the "building" was all done by private contractors; the military input was something else entirely.

"I say, for each patient I will need a 15 square metre cubicle with a ventilator and oxygen and this equipment in a trolley - and their expertise is scaling that up to 300,500 , whatever patients," Whittlestone says. "They are bringing the logistical support for that to happen at incredible speed. I'm used to working in the NHS where to build a hospital is 15 years of planning. This has been done in 15 days." 
He likens the military support they have had to a professional service. "They will take your wish list and provide you with a solution. What I have found fascinating is that I think of the army as people on the battlefield, but in order to provide that frontline service there is a whole organisation of materials, logistics, and programme management-and that's the bit we're tapping into."

And if you have forgotten something or made an error, they are not phased at all: the attitude is one of problem solving not blame. "They are very good at just making it happen; they don't go away and debate it and have committee meetings," says Whittlestone. "They take the instruction and operationalise that for you at great speed."

\section{Chain of command}

This is down to one of the most well known features of military organisations: their hierarchy, with defined chains of command that people respond to quickly, possibly without questioning."

Managing a health service has never much resembled managing an army, and Jones sees the gap as having widened over the years. "The mood in the NHS has been away from command and control, which used to be the culture," he says. "It's been followed by a more distributed leadership style, encouraging local systems to take the lead on sorting out problems." This is only one of many cultural differences between military and civilian organisations, so how will mixed teams of planners be coping with working together?

On this point Norton and Jones are in agreement. The current crisis is pressing, and the goals-particularly the creation of new hospitals-are clear cut. As Norton puts it, "So long as there is a galvanising force, cross agency collaboration can work well." He quotes instances of successful military-civil collaboration such as in the event of terrorist bombing campaigns in London and outbreaks of foot and mouth disease. Other past joint planning ventures include hurricane Irma in
2017, which saw UK forces taking part in the organisation of disaster relief to Caribbean islands.

Whittlestone says that he watched the building of the first Nightingale Hospital in the Excel Centre in London and was impressed by the efficiency with which teams-NHS, military, and private contractors-worked together. A week later the regional rollout began. "The NHS response has been phenomenal, and it shows it can be adaptable. But as clinicians we focus on the patient and the disease in front of us. We reach out to the trolley and take the syringe out of the top drawer, hardly ever considering how it got there, let alone how a hospital was designed and built," he says.

"Working with the military to build a field hospital at pace demonstrates how they are uniquely placed to take the concept of a clinical unit and scale it, perfectly replicated for 300 patients."

The Bristol Nightingale has yet to be used to treat patients, but it is thanks to the input of the British army that it is ready to do so. Whittlestone says, "I have every confidence that when doctors and nurses start to receive patients at Bristol Nightingale Hospital, they will reach out and find a trolley—and the syringe will be in the top drawer."

Some quotes were removed from the original version of this article on 22 May 2020.

I have read and understood BMJ policy on declaration of interests and have no relevant interests to declare.

Related: What the military medic wants you to know about wellbeing and PTSD Listen to his advice for frontline clinicians during covid-19 on the BMJ Talk Medicine podcast: https://soundcloud.com/bmjpodcasts/wellbeing-advice-from-amilitary-medic-to-frontline-clinicians?in=bmjpodcasts/sets/the-bmj-podcast

1 Xinhuanet. Over 10000 military medics working at front line in COVID-19 fight. 2 Mar 2020. http://www.xinhuanet.com/english/2020-03/02/c_138835240.htm

Published by the BMJ Publishing Group Limited. For permission to use (where not already granted under a licence) please go to http://group.bmj.com/group/rights-licensing/ permissions 